\title{
Blessedly forgetful and blissfully unaware: a positivity bias in memory for (re)constructions of imagined past and future events
}

\author{
Belgin Ünal ${ }^{\mathrm{a}, \mathrm{b}}$ and Miri Besken (10 ${ }^{\mathrm{a}}$ \\ ${ }^{a}$ Department of Psychology, Bilkent University, Çankaya/Ankara, Turkey; ${ }^{b}$ Department of Psychology, University of Illinois at Urbana- \\ Champaign, Champaign, IL, USA
}

ABSTRACT

People frequently consider the alternatives of the events that can happen in the future and of the events that already happened in the past in everyday life. The current study investigates the effects of engaging in imagination of hypothetical future (Experiment 1) and past (Experiment 2) events on memory and metamemory. We demonstrate, across two experiments, that imagination of positive future and positive past events yielded greater memory performance than negative events, as well as receiving higher vividness and plausibility ratings. In addition, simulation of a negative event occurring positively in the future or having occurred positively in the past produced higher memory performance, compared to simulation of a positive event occurring / having occurred negatively. However, participants' predictions for their subsequent memory performance did not reflect their increased tendency to remember positive or could-be / could-have-been positive events neither for future nor past reconstructions. These findings are interpreted in the framework of positivity bias which suggests that people have a tendency towards positivity when simulating future events; and we extend this positivity bias to reconstructions of the hypothetical past events as well.
ARTICLE HISTORY

Received 12 January 2020

Accepted 22 June 2020

\section{KEYWORDS}

Episodic memory; imagination of hypothetical past and future; metamemory; positivity bias; fluency

\section{"Blessed are the forgetful, for they get the better even of their blunders". \\ Nietzsche, from Beyond Good and Evil, 1217 (Nietzsche, 2002)}

Recollection of episodic memory, memory for everyday personal experiences (Tulving, 2002), is widely accepted to be a reconstructive process rather than being an exact reproduction of the past (Bartlett, 1932; Hassabis \& Maguire, 2007; Schacter, 2012). Although one might intuitively think that episodic memory is mostly concerned with past events, studies have shown that episodic memory is also linked with imagining episodes that might happen in the future, episodic future thinking (Atance \& O'Neill, 2001; Schacter et al., 2012), and imagining plausible alternative versions of the episodes that already occurred in the past, episodic counterfactual thinking (De Brigard et al., 2013; De Brigard \& Parikh, 2019; Roese, 1997). It has been suggested that these two cognitive processes rely heavily on episodic memory, and they share certain commonalities, where evidence comes both from neuropsychological (Addis et al., 2009; De Brigard et al., 2013; Van Hoeck et al., 2013) and behavioural studies (De Brigard et al., 2016; De Brigard \& Giovanello, 2012; Özbek et al., 2017). Although both concepts have derived from the construct of episodic memory, there is also a body of research showing that these processes have some distinct characteristics that make them distinguishable from episodic memory, as well as from one another (for a review, see Schacter et al., 2015).

Accordingly, despite having comparable constructive processes, one critical distinction between remembering the past and imagining the future is that people tend to conceive their personal futures as being emotionally more positive than their past (Grysman et al., 2013; Shepperd et al., 2013). Newby-Clark and Ross (2003) showed that it took longer time to simulate negative future events than positive future events, whereas there was no such difference found between simulating positive and negative past events. Rasmussen and Berntsen (2013) revealed that positive future events received higher phenomenological ratings on measures of sensory imagery, reliving, and rehearsal than negative future events, while these differences were smaller, if not completely absent, for positive and negative past events. Grysman et al. (2015) demonstrated that future events received higher positivity ratings than past events across five different age groups. Moreover, positive future simulations tended to include more social content indicators than negative future simulations (Painter \& Kring, 2015), and were associated with greater feelings of pre-experiencing (D'Argembeau \& Van Der Linden, 2004).

Although dramatically less is known about episodic counterfactual thinking, it has been suggested that unlike

CONTACT Miri Besken mbesken@bilkent.edu.tr Faculty of Economics, Administrative and Social Sciences, Department of Psychology, Bilkent University, Çankaya/Ankara 06800, Turkey 
future simulations, people engage in counterfactual thinking more frequently following a negative event rather than a positive event (Roese \& Morrison, 2009), which makes upward counterfactuals (simulating how an event might have been better) more prevalent than downward counterfactuals (simulating how an event might have been worse). For clarity and ease of understanding, we will refer to downward counterfactuals as "would-be-negative" and upward counterfactuals as "would-be-positive" counterfactuals throughout this paper. De Brigard and Giovanello (2012) found that episodic counterfactuals were rated as being emotionally less positive and less intense than future simulations and episodic memories. Özbek et al. (2017) also showed that episodic counterfactuals were rated as less important, less positive, and less central to one's life story and identity than future projections were. Taken together, people have a more positive outlook and are more optimistic for their personal futures (Schacter et al., 2012; Sharot, 2011; Sharot et al., 2007; Szpunar, 2010; Weinstein, 1980), while they are more likely to imagine how negative events could have had a good outcome rather than how positive events could have had a bad outcome (Byrne, 2016).

Even though would-be-positive counterfactuals are more commonplace and they have a differential effect on emotion, Gerlach et al. (2014) found no role of valence in terms of the effects of episodic counterfactual thinking on memory. Gerlach et al. showed that engaging in episodic counterfactual thinking can distort the memory for the original event, by resulting in a form of "internally generated misinformation", and it does so regardless of the valence of the memory. On the contrary, for future projections, Szpunar et al. (2012) revealed that when people are asked to remember positive, negative, and neutral future events, the details associated with negative simulations are remembered more poorly than the details associated with positive and neutral events over time, and this facilitates the recollection of future events through "rose-colored spectacles". Overall, experimental evidence suggests that a positivity bias is found in memory for simulated future events (Sharot et al., 2007; Szpunar et al., 2013), although counterfactual thinking seems to operate counter to this positivity bias (Nasco \& Marsh, 1999).

Unlike counterfactual simulation, which juxtaposes an event that did occur against its alternative that is known to not have occurred, in the present study we deal with the imagination of alternative versions of past and future hypothetical events. This procedure of imagining an alternative version of a hypothetical event is similar to counterfactual thinking in the sense that it requires people to either repeat the same simulation or juxtapose an alternative simulation to a previously simulated event. Even though the simulated events are not factual, we expect that simulating hypothetical episodes will mimic the counterfactual thinking process while giving us more control over the experimental design. Accordingly, one of the aims of the present study is to investigate how positive and negative episodes or their alternative outcomes could affect subsequent recollection and we do so by using a comparable set of stimuli for both future and past episodes. When researchers find mnemonic differences across past and future simulations of events, one possibility is that participants might take into consideration whether they have to reconcile with these events or not. While individuals have to reconcile with actual events that happened earlier in life, such a limitation does not exist for future simulations. Thus, the more positive outlook and higher memory performance for simulated future might come from the knowledge that actual past events cannot be changed and thinking of alternative outcomes for irreversible events is futile, limiting the effortful elaboration of past events and their counterfactual alternatives. This, in turn, may lead to memory differences across simulated versions of past and future events. The other possibility is that hypothetical action thoughts aimed at future and at past might function in different ways by the mere virtue of being aimed at different temporal orientations. In that case, regardless of whether the event is hypothetical or not, one should find differences across simulations oriented at the future or the past. By using comparable materials for past and future simulations, the current study can clarify whether and how temporal orientation might contribute to memory differences. If it is the experienced factuality of the events that induces memory differences across past and future simulations, because all the events are imagined in the current design, there should be no differences across future simulations (Experiment 1) and past simulations (Experiment 2) in terms of actual memory performance. Alternatively, if the temporal orientation of the simulation is important, the general pattern across experiments for actual memory performance may be different.

In addition to memory, the present study also investigates the effects of imagination of past and future hypothetical events on metamemory, which refers to people's beliefs and predictions about how their memory operates. Although there are studies showing that people can accurately predict their subsequent memory performance (Nelson \& Dunlosky, 1991), other studies show that under certain circumstances there might be mismatches between people's memory predictions and actual memory performance (Benjamin et al., 1998; Besken, 2016, 2018; Besken \& Mulligan, 2013; Yue et al., 2013). Emotional valence is one factor that sometimes causes a mismatch between predicted and actual memory performance. Studies have typically shown that emotional stimuli produce higher memory predictions than neutral stimuli (Hourihan et al., 2017; Nomi et al., 2013; Tauber \& Dunlosky, 2012; Zimmerman \& Kelley, 2010) even though emotional stimuli do not always lead to increased memory performance (e.g., Hourihan \& Bursey, 2017; Hourihan et al., 2017, exp3; Witherby \& Tauber, 2018). Moreover, most of the time, increased memory predictions for emotional stimuli 
only emerge when emotional stimuli are compared with neutral stimuli (Hourihan et al., 2017), not when broad emotional categories of stimuli (e.g., positive vs. negative valence items) (Nomi et al., 2013) or fine-grained-categories of stimuli (e.g., sad, angry and afraid faces) are compared with each other (Witherby \& Tauber, 2018). Thus, even when participants may remember positivelyvalenced items more than negatively-valenced items, this may not be reflected in memory predictions, as long as neutral items are not introduced to the encoding list.

Instead of emotionality, participants may base their predictions on other factors, such as fluency-"the metacognitive experience of ease or difficulty associated with a cognitive process" (Alter \& Oppenheimer, 2008, p. 162). If we were to evaluate the difficulty level of cognitive tasks and place them on a spectrum from effortless to very effortful, this, in turn, would place the metacognitive experiences on a spectrum from very fluent to disfluent, respectively (Alter \& Oppenheimer, 2009). The studies utilising metacognitive judgments of learning (JOLs), the predictions people give about the likelihood of remembering an item in a later memory test, typically show that participants tend to give higher $\mathrm{JOL}$ ratings to easily or fluently processed items, (Benjamin et al., 1998; Besken, 2016, 2018; Besken \& Mulligan, 2013; Koriat \& Ma'ayan, 2005; Rhodes \& Castel, 2008, 2009; Yue et al., 2013), even though the actual memory performance may not always match with these metacognitive predictions. In line with this, it is possible that imagining a possible future and past event might also be affected by the fluency of these processes. Despite the fact that imagining and reconstructing past or future rely on episodic memory, they include some additional steps; such as manipulating the details of an event to simulate an alternative outcome. This might increase the cognitive load of these processes, which will make them conceptually less fluent than simply imagining a future or past episode in the same way that they were previously encoded. Thus, metacognitive judgments of learning for reconstructions of the future or past episodes might potentially be sensitive to fluency or valence manipulations. The present study seeks to investigate what manipulations impact metamemory in the identical or alternative reconstruction of hypothetical past and future episodes. This is, to our knowledge, the first experimental study that investigates people's memory predictions and actual memory performance for such past and future positive and negative conditional simulations.

In order to investigate these issues, we carried out two experiments. The design was a modification of Gerlach et al. (2014). In their study, participants were given everyday life scenarios to listen to and simulate and were subsequently asked to imagine alternative outcomes of these scenarios. Gerlach and her colleagues' aim was to investigate the effects of counterfactual thinking on memory and they found that engaging in counterfactual thinking following an episode might lead to source confusion. With a similar design to that of Gerlach et al., in the present study, participants were given brief scenarios, each depicting an everyday life situation that takes place in the future (Experiment 1) and in the past (Experiment 2); and asked to imagine themselves experiencing each scenario, as well as providing vividness and plausibility ratings. Half of these scenarios were positive, and the other half was negative. Then, participants were given the same scenarios with the last few words missing and were asked to complete the scenario either with the identical outcome that they read in the previous phase, or with an alternative outcome which has a different valence than the original scenario. They also gave itemby-item JOLs to indicate their confidence of recalling these outcomes (identical vs alternative) on a subsequent memory test. Following a 3 min distraction, participants were given the memory test in which the titles of the scenarios were provided as cues and they were asked to write down the consequence of the scenario with one sentence, either the identical outcome or the alternative outcome, based on the condition in which they completed the scenario.

\section{Experiment 1}

The goal of Experiment 1 was to investigate how potential scenarios of positive and negative episodes in the future influence actual memory performance and memory predictions if participants have to simulate them identically or with an alternative consequence in the opposite valence. On the basis of current literature, we made the following predictions: Concerning the memory performance, if positivity bias exists for future simulations, participants should remember positive events more easily than negative events. Moreover, memory performance for wouldbe-positive alternatives for future events should be higher than the memory performance for would-be-negative alternatives, since would-be-positive alternatives involve simulating how an event with a negative outcome could have turned out positive. Concerning the reaction times of simulations, we expect to see that the onset of the response and the duration of typing will take a longer time for alternative simulation as compared to identical simulation, because alternative consequence simulation may be conceptually more difficult than the identical simulation. If that is the case, when participants are simulating future events in the identical format, they should give higher JOLs to identical simulation scenarios than alternative simulation scenarios, because simulating an alternative consequence requires more effort than an identical simulation.

\section{Method}

\section{Participants}

The experiment closest to the current study in design, Gerlach et al. (2014) Experiment 1, used 24 adults per 
group. Other studies that investigate JOLs for processing fluency (e.g., Besken, 2018; Mueller et al., 2013) or emotions (e.g., Hourihan et al., 2017; Hourihan \& Bursey, 2017) usually use sample sizes ranging from 20 to 40 per group. A statistical power analysis through G-power (Faul et al., 2009) revealed that a sample size of 30 was necessary to detect a middle-sized effect of $f=.25$ with a power of .90 , at an alpha of .05. In order to ensure that all four counterbalance conditions were shown to an equal number of participants, thirty-two undergraduate students between the ages of 18-30 from Bilkent University were recruited in the experiment in exchange for course credit. All participants were native in Turkish. The study was approved by Bilkent University Ethics Committee.

\section{Materials and design}

The emotional valence of the scenarios (positive and negative) was manipulated within subjects. The stimulus set consisted of 80 brief scenarios, created by the first author, all of which depicts an everyday life situation that can occur in the future. Each scenario was 3-5 sentences long, with 2-4 words long titles that reflected the content of the scenario. Each scenario had a version with a negative and a positive outcome. The outcome valence of the scenarios was counterbalanced across participants such that when one participant read the scenario with a positive outcome, the next one read the same scenario with a negative outcome. Everything in the negative and positive scenarios was the same except the outcome valence. The outcome valence of the scenarios was evaluated by an independent group of twenty participants through an online survey. Participants were presented with both positive and negative outcomes of the same scenario and asked to choose the more positive version. They rated positive scenarios to be more positive than negative scenarios $95.69 \%$ of the time. In the main experiment, each participant read 40 negative and 40 positive scenarios in total in the encoding phase. The simulation condition (alternative trials vs identical trials) was also manipulated within subjects. A copy of materials translated to English can be found in supplementary online files.

\section{Procedure}

All participants were tested individually in a small testing room. The experiment consisted of an encoding phase, a simulation phase, a distractor phase, and a memory test phase. All instructions were presented both verbally and on the computer screen before each phase.

In the encoding phase, participants were presented with positive and negative scenarios, each with a title, one at a time through the computer screen, and each scenario remained on the screen for a 15-s duration. They were asked to read the scenarios and imagine themselves experiencing this situation in the future. An example of a scenario used in the experiment (translated to English from Turkish) can be found in Figure 1, with its positive and negative versions. After reading each scenario, participants provided ratings on a 5 -point scale for vividness ( $1=$ not vivid at all, $5=$ very vivid), and plausibility ( $1=$ not plausible at all, $5=$ very plausible). This was done to provide participants with an opportunity to process the scenarios more deeply. They entered their answers using the corresponding key on the keyboard and pressed ENTER to proceed to the next scenario. After completing all 80 scenarios, they moved on to the simulation phase.

In the simulation phase, the same scenarios, again with their titles, were presented to the participants, but this time, the last few words of the scenarios were missing, and participants were instructed to complete the scenario in accordance with the simulation condition. There were two simulation conditions: Identical scenario and alternative scenario. Identical scenario trials were labelled with the phrase "Identical Scenario" (Ayn Hikaye in Turkish) and participants were asked to press $A$ to proceed. Pressing $A$ initiated the display of the title and the scenario underneath the identical scenario prompt. In the identical scenario trials, participants were asked to complete the scenario in the same way they read and imagined it during the encoding phase. Alternative scenario trials were labelled with the phrase "Counterfactual Scenario" (Varsayımsal Hikaye in Turkish) and participants pressed $V$ to see the title and scenario underneath the alternative scenario prompt. In the alternative consequence scenario trials, participants were asked to complete the scenario with an alternative outcome that has a different valence than the one they read at the encoding phase. Note that in the alternative trials, if the scenario originally had a positive outcome, participants needed to write down a negative outcome (would-be-negative alternative); whereas if the scenario originally had a negative outcome, participants needed to complete the scenario with a positive outcome (would-be-positive alternative). There is an example of the identical and alternative scenario conditions for the positive and negative versions of the same scenario in Figure 1. Participants used the keyboard to type in their completions, and the programme recorded participants' first keypress latency (the time between the onset of the question to the time participants pressed any key) and total typing latency (the time between first keypress and pressing ENTER key) for each response. When participants pressed ENTER, the programme moved on to the JOL screen. In the JOL screen, participants were asked to indicate their prediction of how sure they were that they would remember the consequence of this scenario later in a memory test on a scale from 0 to 100 , where 0 means "I am not sure that I will remember this consequence at all" and 100 means "I am extremely sure I will remember this consequence". They were instructed to use the whole scale to rate their confidence, and type in their answers by pressing the appropriate key on the keyboard. All JOLs were self-paced and on a continuous scale. In the simulation phase, participants completed and provided confidence ratings for 40 alternative and 40 identical scenarios (80 in total), and the presentation of the conditions was counterbalanced across participants so that when one participant completed the scenario with an identical 


\begin{tabular}{|c|c|c|c|c|c|c|c|c|}
\hline & \multicolumn{8}{|c|}{ Scenario Title: Buying a Movie Ticket } \\
\hline & \multicolumn{4}{|c|}{ Experiment 1} & \multicolumn{4}{|c|}{ Experiment 2} \\
\hline & \multicolumn{2}{|c|}{ Positive Scenario } & \multicolumn{2}{|c|}{ Negative Scenario } & \multicolumn{2}{|c|}{ Positive Scenario } & \multicolumn{2}{|c|}{ Negative Scenario } \\
\hline $\begin{array}{c}\text { ENCODING } \\
\text { PHASE }\end{array}$ & \multicolumn{2}{|c|}{$\begin{array}{l}\text { You will go to a movie with your } \\
\text { friend tomorrow evening. } \\
\text { Imagine that your credit card will } \\
\text { not work when you are in the } \\
\text { theater. You will be carrying } \\
\text { cash with you as well. Since you } \\
\text { have cash, you will be able to } \\
\text { buy the movie tickets. }\end{array}$} & \multicolumn{2}{|c|}{$\begin{array}{l}\text { You will go to a movie with your } \\
\text { friend tomorrow evening. } \\
\text { Imagine that your credit card will } \\
\text { not work when you are in the } \\
\text { theater. You will not be carrying } \\
\text { cash with you. Because you do } \\
\text { not have cash, you will not be } \\
\text { able to buy the movie tickets. }\end{array}$} & \multicolumn{2}{|c|}{$\begin{array}{l}\text { You had decided to go to a } \\
\text { movie with your friend last } \\
\text { evening. When you were in the } \\
\text { theater, your credit card did not } \\
\text { work. You were carrying cash } \\
\text { with you as well. Since you had } \\
\text { cash, you could buy the movie } \\
\text { tickets. }\end{array}$} & \multicolumn{2}{|c|}{$\begin{array}{l}\text { You had decided to go to a } \\
\text { movie with your friend last } \\
\text { evening. When you were in the } \\
\text { theater, your credit card did not } \\
\text { work. You were not carrying } \\
\text { cash with you. Because you did } \\
\text { not have cash, you could not buy } \\
\text { the movie tickets. }\end{array}$} \\
\hline \multirow[b]{2}{*}{$\begin{array}{l}\text { SIMULATION } \\
\text { PHASE }\end{array}$} & $\begin{array}{l}\text { Identical } \\
\text { Scenario }\end{array}$ & \begin{tabular}{|l|} 
Would-be- \\
Negative \\
Scenario
\end{tabular} & $\begin{array}{l}\text { Identical } \\
\text { Scenario }\end{array}$ & \begin{tabular}{|l|} 
Would-be- \\
Positive \\
Scenario
\end{tabular} & $\begin{array}{l}\text { Identical } \\
\text { Scenario }\end{array}$ & \begin{tabular}{|l} 
Would-be- \\
Negative \\
Scenario
\end{tabular} & $\begin{array}{l}\text { Identical } \\
\text { Scenario }\end{array}$ & \begin{tabular}{|l|} 
Would-be- \\
Positive \\
Scenario
\end{tabular} \\
\hline & \begin{tabular}{|l|} 
You will go to \\
a movie with \\
your friend \\
tomorrow \\
evening. \\
Imagine that \\
your credit card \\
will not work \\
when you are in \\
the theater. You \\
will be carrying \\
cash with you. \\
"Because I \\
have cash,...
\end{tabular} & $\begin{array}{l}\text { You will go to } \\
\text { a movie with } \\
\text { your friend } \\
\text { tomorrow } \\
\text { evening. } \\
\text { Imagine that } \\
\text { your credit card } \\
\text { will not work } \\
\text { when you are in } \\
\text { the theater. You } \\
\text { will be carrying } \\
\text { cash with you. } \\
\text { "If I don't } \\
\text { have cash,... }\end{array}$ & $\begin{array}{l}\text { You will go to } \\
\text { a movie with } \\
\text { your friend } \\
\text { tomorrow } \\
\text { evening. } \\
\text { Imagine that } \\
\text { your credit card } \\
\text { will not work } \\
\text { when you are in } \\
\text { the theater. You } \\
\text { will not be } \\
\text { carrying cash } \\
\text { with you. } \\
\text { 'Because I } \\
\text { don't have } \\
\text { cash,... }\end{array}$ & $\begin{array}{l}\text { You will go to } \\
\text { a movie with } \\
\text { your friend } \\
\text { tomorrow } \\
\text { evening. } \\
\text { Imagine that } \\
\text { your credit card } \\
\text { will not work } \\
\text { when you are in } \\
\text { the theater. You } \\
\text { will not be } \\
\text { carrying cash } \\
\text { with you. "If I } \\
\text { do have } \\
\text { cash,... }\end{array}$ & $\begin{array}{l}\text { You had } \\
\text { decided to go to } \\
\text { a movie with } \\
\text { your friend last } \\
\text { evening. When } \\
\text { you were in the } \\
\text { theater, your } \\
\text { credit card did } \\
\text { not work. You } \\
\text { were carrying } \\
\text { cash with you. } \\
\text { "Because I } \\
\text { had cash,... }\end{array}$ & $\begin{array}{l}\text { You had } \\
\text { decided to go to } \\
\text { a movie with } \\
\text { your friend last } \\
\text { evening. When } \\
\text { you were in the } \\
\text { theater, your } \\
\text { credit card did } \\
\text { not work. You } \\
\text { were carrying } \\
\text { cash with you. } \\
\text { "If I didn't } \\
\text { have cash,... }\end{array}$ & \begin{tabular}{|l|} 
You had \\
decided to go to \\
a movie with \\
your friend last \\
evening. When \\
you were in the \\
theater, your \\
credit card did \\
not work. You \\
were not \\
carrying cash \\
with you. \\
"Because I \\
didn't have \\
cash,...
\end{tabular} & $\begin{array}{l}\text { You had } \\
\text { decided to go to } \\
\text { a movie with } \\
\text { your friend last } \\
\text { evening. When } \\
\text { you were in the } \\
\text { theater, your } \\
\text { credit card did } \\
\text { not work. You } \\
\text { were not } \\
\text { carrying cash } \\
\text { with you. "If I } \\
\text { had cash,... }\end{array}$ \\
\hline
\end{tabular}

Figure 1. General procedure of experiments. Examples of positive and negative versions of a scenario presented during the encoding phase, and examples of identical, would-be-positive and would-be-negative alternatives that are presented during the simulation phase in Experiments 1 and 2.

outcome, the next participant completed the same scenario with the alternative outcome. These scenarios were further counterbalanced for emotional valence and shown to an equal number of participants in each condition.

After the simulation phase, participants completed a 3 min distractor task that consisted of solving arithmetic math problems presented on the computer screen one at a time. Then, they were given instructions for the test phase. The memory test was in the form of a cued-recall test, whereby the titles of the scenarios were presented on the screen one at a time, and participants were instructed to write down one sentence that reflects the consequence of the scenarios that they completed in the simulation phase. If the participant completed the scenario with an identical outcome, they needed to write down that identical consequence of the scenario. If the participant completed the scenario with an alternative outcome, they needed to write down that alternative consequence. After writing their response, they pressed ENTER to see the next title. They were also told that if they cannot remember the consequence, they can press ENTER to move on to the next title. This phase was self-paced. When they completed the memory test for 80 scenarios, the experiment ended, and debriefing information was displayed on the screen.

\section{Results and discussion}

The results of all the inferential statistics reported throughout this article are reliable at alpha level .05 using a twotailed test.

\section{Data coding}

Same coding procedure was followed for both experiments.

Scheme for simulation. In the simulation phase, following the procedure consisted of typing in an appropriate answer in line with the valence and content of the scenario. For alternative trials, if the scenario was positive, participants needed to complete the scenario with a would-benegative alternative (simulating a worse outcome), whereas if the scenario was negative, participants needed to complete the scenario with a would-be-positive alternative (simulating a better outcome). For identical trials, if the scenario was positive, the response should have had the same positive outcome that it had during the encoding phase, whereas if the scenario was negative, the response should have had the negative outcome that it had during the encoding phase. Participants were considered to have not followed the procedure if they typed in a wrongly-valenced answer, or if the content of their response was completely irrelevant to the content of the scenario that was previously presented in the encoding phase.

Scheme for Recall. In the cued- recall test, participants were given the titles of the scenarios, and asked to write down the consequence of the scenario in the same valence that they completed at the simulation phase (either with the identical or an alternative outcome). Specifically, they were asked to write down one sentence that structurally has two parts: For alternative consequences, the structure was the conditional proposition 
form of "If I ..., then ...", and for identical consequences, the structure was "Because I..., ...". Participants were considered to have given the correct answer if they remembered their response with the correct procedure (identical or alternative) and with the correct valence (positive or negative) and write down the sentence which has two parts that reflect the causal relationship. Participants were considered to give partially correct answer if the response consisted only one part of the sentence that reflects either the correct valence (but not the procedure), or the correct procedure (but not the valence). Accordingly, there was a partial point system where partially correct answers were given a point of .5 , fully correct answers were given a point of 1 . For example, if the correct answer was "Because I have cash, I will (be able to) buy the movie tickets", they were given a full point for a sentence that included both parts, whereas if they said "I have cash" or "I will be able to buy the movie tickets", they were given .5 points. All other answers were considered as wrong and were coded as zero.

Conditional recall was calculated by obtaining the sum of correct recall for each participant for each condition (identical-positive, identical-negative, alternative-positive, alternative-negative) and dividing it with the total number of trials in which the procedure was followed correctly in that condition. The highest point possible for a participant in each condition was 20. The number of trials in which participants did not follow the procedure at the simulation phase was excluded from the analysis, and their score was divided with the remaining total number of trials in which the procedure was followed correctly. Assuming that the participant followed the procedure correctly for all the trials in that given condition, and they recalled all the events successfully, the highest proportional score they can get was 1 .

\section{Plausibility and vividness ratings for positive and negative scenarios at the encoding phase}

The trials in which participants failed to enter a response between 1 and 5 were excluded from vividness (.8\% of trials) and plausibility (.4\% of trials) analysis of ratings. The mean vividness and plausibility ratings were computed for each participant separately for all positive and negative scenarios. The mean ratings for positive and negative scenarios can be seen at the top half of Table 1. A paired-samples t-test showed a significant difference between positive and negative scenarios for vividness ratings, with higher vividness ratings for positive than

Table 1. Means and standard error of the mean (in parentheses) for vividness and plausibility ratings for positive and negative scenarios during the encoding phases in Experiment 1 and Experiment 2.

\begin{tabular}{lccccc}
\hline & \multicolumn{2}{c}{ Vividness } & & \multicolumn{2}{c}{ Plausibility } \\
\cline { 2 - 3 } \cline { 5 - 6 } & Positive & Negative & & Positive & Negative \\
\hline Experiment 1 & $4.03(.09)$ & $3.90(.09)$ & & $3.34(.09)$ & $2.92(.07)$ \\
Experiment 2 & $3.90(.10)$ & $3.67(.13)$ & & $3.42(.08)$ & $2.90(.09)$ \\
\hline
\end{tabular}

negative scenarios, $t(31)=2.39, p=.023, d=.42$. There was also a significant difference between positive and negative scenarios for plausibility ratings. Positive scenarios were rated as more plausible than negative scenarios, $t(31)=4.22, p<.001, d=.75$.

\section{Response time and metamemory at the simulation phase}

The descriptive statistics for procedure compliance, response time, and JOLs are presented in Table 2. The trials in which participants failed to follow the procedure correctly were not significantly different than each other by a Friedman test $(p=.782)$. These trials were excluded from the response time, metamemory, and memory analyses (exclusion rate $=3.9 \%$ ). The median reaction times for the first keypress and total typing time were computed for each participant separately for all identical and alternative trials. Then, the mean of the median reaction times was entered into a repeated measures two-way ANOVA with valence (positive, negative) and procedure (identical, alternative) as repeated factors. As expected, participants' first keypress was significantly faster for identical trials $(M$ $=8621, S E=701)$ than alternative trials $(M=9304, S E=$ 710), $F(1,31)=7.89, M S_{\text {error }}=1915000, p=.009, \eta_{p}^{2}=.203$. However, for total typing time, there was no significant difference between identical and alternative trials $F(1,31)$ =1.53, $M S_{\text {error }}=988437, p=.226, \eta_{p}^{2}=.047$. Neither valence, nor its interaction with procedure yielded any significant difference for total typing time $(F s<1)$.

For the item-by-item JOLs, the trials in which participants failed to enter a rating between 0 and $100(.7 \%$ of trials) were additionally excluded from the metamemory analysis. The mean JOL ratings were computed for each participant separately for all identical and alternative trials. The analysis revealed a significant main effect of procedure, $F(1,31)=12.10, M S_{\text {error }}=28.96, p=.002, \eta_{p}^{2}=.281$. Participants gave higher confidence ratings for identical trials $(M=65.38, S E=3.56)$ than alternative trials $(M=$ $62.01, S E=3.72$ ), as expected. Neither valence nor the interaction was significant for item-by-item JOLs.

\section{Cued-recall performance at the testing phase}

The descriptive statistics for cued-recall performance are presented in Table 3. The proportion of correct recall was computed for each participant. There was no main effect of valence, positive and negative scenarios were remembered equally $(F<1)$. However, there was a main effect of the procedure, participants had higher cued-recall for identical $(M=.59, S E=.05)$ than alternative trials $(M=.45, S E$ $=.04), F(1,31)=4.14, M S_{\text {error }}=0.16, p=.050, \eta_{p}^{2}=.118$. Critically, there was a significant interaction between procedure and emotional valence, $F(1,31)=24.75$, $M S_{\text {error }}=.01, p<.001, \eta_{p}^{2}=.444$. Post hoc t-tests revealed that for identical trials, positive scenarios yielded better memory than negative scenarios, $t(31)=2.40, p=.023, d$ $=.42$; whereas for alternative trials would-be-positive scenarios yielded better memory than would-be-negative 
Table 2. Means and standard error of the mean (in parentheses) for procedure follow, first keypress latency, response completion latency, and memory predictions for Experiment 1 and Experiment 2.

\begin{tabular}{|c|c|c|c|c|c|c|c|c|c|}
\hline & & \multicolumn{2}{|c|}{ Procedure compliance } & \multicolumn{2}{|c|}{ First keypress (in ms) } & \multicolumn{2}{|c|}{$\begin{array}{l}\text { Response completion } \\
\text { (in ms) }\end{array}$} & \multicolumn{2}{|c|}{$\begin{array}{c}\text { Memory predictions } \\
\text { (out of 100) }\end{array}$} \\
\hline & & Positive & Negative & Positive & Negative & Positive & Negative & Positive & Negative \\
\hline \multirow[t]{2}{*}{ Experiment 1} & Identical & $\begin{array}{l}.96 \\
(.01)\end{array}$ & $\begin{array}{l}.96 \\
(.01)\end{array}$ & $\begin{array}{l}8670 \\
(718)\end{array}$ & $\begin{array}{l}8572 \\
(722)\end{array}$ & $\begin{array}{l}6507 \\
(276)\end{array}$ & $\begin{array}{l}6590 \\
(284)\end{array}$ & $\begin{array}{l}65.41 \\
(3.68)\end{array}$ & $\begin{array}{l}65.36 \\
(3.53)\end{array}$ \\
\hline & Alternative & $\begin{array}{l}.96 \\
(.01)\end{array}$ & $\begin{array}{c}.96 \\
(.01)\end{array}$ & $\begin{array}{l}9454 \\
(704)\end{array}$ & $\begin{array}{l}9162 \\
(745)\end{array}$ & $\begin{array}{l}6279 \\
(295)\end{array}$ & $\begin{array}{l}6383 \\
(322)\end{array}$ & $\begin{array}{l}61.16 \\
(3.78)\end{array}$ & $\begin{array}{l}62.99 \\
(3.73)\end{array}$ \\
\hline \multirow[t]{2}{*}{ Experiment 2} & Identical & $\begin{array}{c}.98 \\
(.01)\end{array}$ & $\begin{array}{c}.98 \\
(.01)\end{array}$ & $\begin{array}{l}7651 \\
(706)\end{array}$ & $\begin{array}{l}7682 \\
(671)\end{array}$ & $\begin{array}{l}6374 \\
(378)\end{array}$ & $\begin{array}{l}5960 \\
(381)\end{array}$ & $\begin{array}{l}66.50 \\
(3.34)\end{array}$ & $\begin{array}{l}66.91 \\
(3.22)\end{array}$ \\
\hline & Alternative & $\begin{array}{c}.93 \\
(.02)\end{array}$ & $\begin{array}{c}.91 \\
(.03)\end{array}$ & $\begin{array}{l}8474 \\
(716)\end{array}$ & $\begin{array}{l}8560 \\
(828)\end{array}$ & $\begin{array}{l}6677 \\
(381)\end{array}$ & $\begin{array}{l}6667 \\
(340)\end{array}$ & $\begin{array}{l}63.21 \\
(3.09)\end{array}$ & $\begin{array}{l}64.45 \\
(3.28)\end{array}$ \\
\hline
\end{tabular}

scenarios, $t(31)=3.39, p=.002, d=.60$. For positive scenarios, identical trials resulted in better memory than alternative trials, $t(31)=3.32, p=.002, d=.59$. However, for negative scenarios, there was no difference between identical and alternative trials $(p=.460)$.

In order to see whether actual recall performance was affected by JOL ratings, a multilevel binary logistic regression was conducted at in three steps, with recall performance as the dependent variable (1: recall, 0: did not recall), using $\mathrm{R}$ core package and Ime4 package (Bates et al., 2011; R Core Team, 2013). Invalid JOL trials and trials in which participants did not follow the procedure were excluded from the analyses (2.2\%). When participants were able to partially recall the item, this was coded as 1 , as they had access to the item. JOLs were centred separately within subjects for each participant and between subjects, as previously described in Hertzog et al. (2013). The null model (Model 1) consisted of participants added as a random effect to predict recall performance with a fixed slope. In Model 2, JOLs centred within participants as well as a random slope for within participants JOLs per subject with no intercept was added to Model 1. This model tests whether the odds of the participant predicting their recall performance increases as JOLs increase for each participant. Model 2 showed a significant improvement through a log likelihood ratio test (LRT), $X^{2}(2)=26.286, p$ $<.001$. The fixed estimate for within-participants JOLs $(b$ : $.011, S E: .002)$ was significant $(z=4.91, p<.001)$, showing that the odds of recalling an item increased by .01 for a 1-point increase in JOLs. In Model 3, JOLs centred

Table 3. Means and standard error of the mean (in parentheses) for conditional proportion correct recall for Experiment 1 and Experiment 2.

\begin{tabular}{llcc}
\hline \multicolumn{4}{c}{ Conditional proportion correct recall } \\
\hline & $\begin{array}{c}\text { Positive (identical)/ } \\
\text { Would-be-negative } \\
\text { (alternative) }\end{array}$ & $\begin{array}{c}\text { Negative (identical) / } \\
\text { Would-be-positive } \\
\text { (alternative) }\end{array}$ \\
\hline Experiment & Identical & $.62(.05)$ & $.55(.05)$ \\
1 & Alternative & $.40(.05)$ & $.50(.04)$ \\
Experiment & Identical & $.65(.04)$ & $.54(.04)$ \\
2 & Alternative & $.45(.05)$ & $.56(.05)$ \\
\hline
\end{tabular}

*When positive scenarios are constructed with an alternative outcome in the simulation phase, their valence becomes negative, resulting in would-benegative alternatives.

**When negative scenarios are constructed with an alternative outcome their valence becomes positive, resulting in would-be-positive alternatives. between participants for each encoding condition and story type was added to Model 2 in order to assess whether between-subjects JOL variations increased the odds of recall. Model 3 did not show a significant improvement with the addition of JOLs centred between subjects through LRT, $X^{2}(1)=0.098, p=.754$. Thus, participants with higher JOLs did not differ significantly from participants with lower JOLs in terms of their actual recall.

In terms of actual memory performance, the results reveal that participants have a tendency to remember positive events for the identical procedure and how it could have turned out positive for the alternative procedure, consistent with the literature in which positivity bias often characterises the future thinking process (Sharot, 2011; Sharot et al., 2007).

The experiment confirms that memory predictions for future simulations are higher when they are simulated in the same way, as compared to when they are simulated with a different consequence. Identical simulation is less effortful, which might lead to higher JOLs, consistent with various types of fluencies such as encoding fluency (Castel et al., 2007; Hertzog et al., 2003), retrieval fluency (Benjamin et al., 1998; Koriat \& Ma'ayan, 2005), perceptual fluency (Besken, 2016; Besken \& Mulligan, 2013; Rhodes \& Castel, 2008, 2009; Yue et al., 2013). In contrast, JOLs are not sensitive to emotional valence, even though this factor influences actual cued-recall performance, revealing that participants are not aware of their positivity bias for their memory. Emotional valence of items typically becomes more prominent, when they are contrasted against neutral items (Hourihan et al., 2017), not when two broad categories of emotional valence are being compared with each other (Nomi et al., 2013).

\section{Experiment 2}

When potential events that might happen in the future are simulated in identical or alternative manners, participants have a tendency to remember positive or wouldbe-positive versions of the potential events more often than negative or would-be-negative versions. Previous research has shown that participants are typically more positive about the future, as compared to the past (Shepperd et al., 2013). Experiment 2 investigated whether 
similar results would be obtained, if the events were originally imagined having happened in the past. We make the following predictions: In terms of memory performance, if participants have a positivity bias for potential past events as much as the potential future events, superior memory performance for positive and wouldbe-positive simulations should persist. On the other hand, if positivity bias occurs only for future events, we should not see an elevated memory for positive or would-be-positive past episodes.

In terms of reaction times, we expect people will be slower when they engage in alternative consequence simulation of the episodes as compared with identical simulations, because alternative consequence construction is a more effortful process. Hence, in terms of memory predictions, we predict that JOLs should be higher for identical than alternative scenarios since simulating events identically should lead to less effort as compared to generating a plausible, different-valenced event. As in line with the previous experiment, no effects are hypothesised for emotional valence of the scenarios, as these scenarios are not being contrasted against neutral scenarios, even when there are actual memory performance differences for emotional valence.

\section{Method}

\section{Participants}

Thirty-two undergraduate students between the ages of 18-30 from Bilkent University who did not participate in the first experiment participated in exchange for course credit. All participants were native in Turkish. The power analysis used in Experiment 1 was used to determine sample size.

\section{Materials, design, and procedure}

The same scenarios used in Experiment 1 were used, but instead of future, each scenario was framed with past tense, and participants were instructed to imagine themselves having experienced these scenarios in the past rather than in the future. An example of a scenario used in Experiment 2 can be seen in Figure 1. The design and procedure were identical to that in Experiment 1. Participants read 80 scenarios (40 positive and 40 negative), and they provided vividness and plausibility ratings on a 5-point scale. Then, they were presented with the same scenarios whose last few words were missing, and they completed the scenario either with an identical outcome or an alternative outcome, and the programme recorded their first keypress and total typing latencies. After completing each scenario, they provided a JOL to indicate the likelihood of remembering the consequence of this scenario in a subsequent memory test. The JOLs were self-paced as in Experiment 1. The cued-recall memory test was identical to that used in Experiment 1.

\section{Results and discussion}

Plausibility and vividness ratings for positive and negative scenarios at the encoding phase

The trials in which participants failed to enter a response between 1 and 5 were excluded from vividness $(.3 \%$ of trials) and plausibility (.4\% of trials) analysis of ratings. The mean vividness and plausibility ratings for positive and negative scenarios can be seen at the bottom half of Table 1. The difference between positive and negative scenarios for vividness ratings was significant, positive scenarios were rated as more vivid than negative scenarios, $t(31)=2.50, p=.018, d=.44$. The difference between positive and negative scenarios for plausibility ratings was also significant, participants gave higher ratings for positive scenarios than negative scenarios, $t(31)=5.33, p$ $<.001, d=.94$.

\section{Response time and metamemory at the simulation phase}

The descriptive statistics for procedure compliance, response time, and JOLs can be seen in Table 2. The trials in which participants failed to follow the procedure correctly were significantly different than each other by a Friedman test $(p=.001)$. Participants followed the procedure more easily in identical trials than alternative trials for both positive $(p=.007)$ and negative-valenced $(p<.001)$ conditions. Still, procedure compliance was quite high for all conditions. The trials in which participants failed to follow the procedure $(5.2 \%$ of trials) were excluded from response time, metamemory, and memory analyses. Participants' first keypress was significantly faster for identical trials $(M=7667, S E=671)$ than for alternative trials $(M=8517, S E=748), F(1,31)=5.57$, $M S_{\text {error }}=4150000, p=.025, \eta_{p}^{2}=.152$. It also took more time to complete the responses for alternative trials $(M=6672$, $S E=339)$ than for identical trials $(M=6167, S E=360)$, $F(1,31)=12.21, M S_{\text {error }}=667535, p=.001, \eta_{p}^{2}=.283$. Again, valence did not yield any significant difference for the response time latencies.

The trials in which participants did not enter a JOL rating between 0 and 100 (.2\%) were additionally excluded from the JOL analyses. This time, the difference between identical and alternative trials did not reach significance, $F(1,31)$ $=2.41, M S_{\text {error }}=109.46, p=.131, \eta_{p}^{2}=.072$. Neither valence nor the interaction was significant, $F_{\mathrm{s}}<1$.

\section{Cued-recall performance at the testing phase}

The descriptive statistics for cued-recall performance are presented in Table 3. The same pattern observed in Experiment 1 was found here as well. There was no main effect of valence: positive and negative scenarios were remembered equally $(F<1)$. However, there was a main effect of the procedure such that participants had better recall performance for identical trials $(M=.59, S E=.03)$ than for alternative trials $(M=.50, S E=.05), F(1,31)=4.87, M S_{\text {error }}$ $=.053, p=.035, \eta_{p}^{2}=.136$. Moreover, there was a significant interaction between valence and procedure for cued recall, 
$F(1,31)=18.52, M S_{\text {error }}=.021, p<.001, \eta_{p}^{2}=.374$. Post hoc $t-$ tests showed that for identical trials, there was a significant difference between positive and negative scenarios, where positive ones were remembered more than negative ones, $t(31)=3.38, p=.002, d=.60$. For alternative trials, there was a significant difference between would-be-negative and would-be-positive scenarios as well, would-be-positive scenarios yielded higher memory performance than would-be-negative ones, $t(31)=3.67, p=.001, d=.65$. For positive scenarios, identical trials resulted in higher memory than alternative trials, $t(31)=4.38, p<.001, d$ $=.77$. Again, for negative scenarios, there was no difference between identical and alternative trials ( $p=.694)$.

In order to see whether actual recall performance was affected by $\mathrm{JOL}$ ratings, a multilevel logistic regression was conducted at in three steps, with recall performance as the dependent variable, as in Experiment $1.1 .2 \%$ of trials were excluded from the analyses for procedure non-compliance and invalid JOLs. The null model (Model 1) consisted of participants added as a random effect to predict recall performance with a fixed slope. In Model 2, JOLs centred within participants as well as a random slope for within participants JOLs per subject were added to Model 1. Model 2 showed a significant improvement with the addition of a fixed slope through a log likelihood ratio test(LRT), $X^{2}(2)=31.615, p<.001$. The fixed estimate for within-participants JOLs (b: .010, SE: .003) was significant $(z=2.93, p=.003)$, showing that the odds of recalling an item increased by .01 for a 1-point increase in JOLs. In Model 3, JOLs centred between participants was added to Model 2 in order to assess whether between-subjects JOL variations increased the odds of recall. Model 3 did not show a significant improvement with the addition of JOLs centred between subjects through LRT, $X^{2}(1)=$ $0.0561, p=.813$. Thus, participants with higher JOLs do not significantly differ from participants with lower JOLs in terms of their recall performance.

These results demonstrate that there is a positivity bias influencing the memory such that people better remember positive past episodes for identical simulation and wouldbe-positive past episodes for alternative simulation conditions. Although it has been suggested that optimism bias is present for future events (Sharot et al., 2007; Weinstein, 1980), it possibly has an influence on remembering the imagined past as well.

On the other hand, memory predictions did not yield any significant result, although people were significantly slower when simulating alternative condition than identical condition and descriptively, we were able to see the same pattern observed in Experiment 1 for JOLs. Again, there was no effect for emotional valence of the scenarios, showing that participants are not aware of their inclination to remember positive or would-be-positive scenarios.

\section{Cross-experimental analysis}

To see whether or not there is an interaction between valence and temporal orientation for JOL and memory performance across experiments, we performed a repeated measures two-way ANOVA as valence and procedure within-subjects factors and Experiment 1 and 2 as between-subject factor. For JOLs, this interaction was neither significant for valence $(p=.956)$ nor for procedure ( $p=.834)$. Similarly, for recall performance, neither the interaction with valence $(p=.540)$ nor with procedure ( $p$ $=.523$ ) was significant.

\section{General discussion}

In the present experiments, we aimed to investigate how simulating positive and negative hypothetical episodes in the future (Experiment 1) and in the past (Experiment 2) influences actual memory performance if participants have to construct them with an identical or alternativevalenced outcome. We also investigated the effects of these manipulations on memory predictions. Participants were presented with a set of positive and negative scenarios, then asked to simulate these episodes either with the identical consequence or with an alternative consequence, and provide predictions of future memory performance for each, followed by a cued-recall test.

One goal of the study was to investigate how engaging in construction of an alternative outcome for positive and negative episode would influence memory for past and future. Various studies documented that people's thoughts tend to be positively biased for their personal futures (Barsics et al., 2016; Newby-Clark \& Ross, 2003; Özbek et al., 2017; Rasmussen \& Berntsen, 2013; Sharot, 2011; Sharot et al., 2007; Weinstein, 1980). As we expected and in line with the previous research, we found that the memory was better for positive future episodes for identical simulation and would-be-positive future episodes for alternative simulation in Experiment 1. Critically, we have found the same recall pattern for past episodes in Experiment 2, which indicates that this bias towards positivity persists when people simulate episodes which hypothetically happened in the past. Although the simulated events in the present study are not factual, the process of repeating the same simulation or an alternative simulation to a previously presented event resembles counterfactual thinking. Hence, the superior memory for positive and would-be-positive past events is quite interesting, as counterfactual thinking of past is generally thought to operate counter to such an optimism bias (Nasco \& Marsh, 1999). The study shows that having higher memory performance for how a negative episode might have had a positive outcome is actually another side of this optimism bias observed in memory. Furthermore, in a study where reasons for engaging in counterfactual thinking has been examined, Özbek et al. (2018) have revealed that counterfactual thinking is more commonly used for self-reflection and social sharing purposes, rather than ruminations and generative concerns. This finding, although counter-intuitive, implies that episodic counterfactual thinking does not necessarily function 
against the positivity bias. In addition, at the encoding phase, we asked for vividness and plausibility ratings in order to induce a deeper process of the episodes. Interestingly, people gave higher vividness and plausibility ratings for positive scenarios than for negative scenarios both for future and past. Hence, it is possible that optimism bias starts during the encoding of the information into the memory, and influences the pattern observed in recall performance.

Another goal of the present study was to examine whether people make different predictions for their subsequent memory performance if the cognitive process is solely imagining an event as it is (identical simulation) versus imaging the event with an alternative/differentlyvalenced outcome (alternative simulation). We assumed that simulating a previously-known episode with an alternative outcome is a cognitively more demanding process since it requires imagining the original episode and then imagining the alternative and plausible version of it. Hence, it was hypothesised that engaging in alternative simulation would lead to lower memory predictions than identical simulation considering construction of an alternative consequence is a more effortful process. As expected, people gave higher JOLs for identical future simulations than alternative future simulations in Experiment 1 . This result is consistent with the literature, when the task calls for more effort, people tend to think they will have worse memory for it than a less effortful task (Begg et al., 1989; Benjamin et al., 1998; Castel et al., 2007; Hertzog et al., 2003; Koriat \& Bjork, 2006; Miele et al., 2011). However, the difference between alternative simulation and identical simulation for past episodes did not reach statistical significance. Özbek et al. (2017) showed that episodic counterfactuals were rated as less important, less positive, and less central than future projections. These findings for imagining alternative outcomes for the past episodes might perhaps also generalise to JOLs as well, since JOLs are technically judgments about memory, and the cognitive effort that one puts in to change the past may feel more trivial, compared with future simulation, eliminating the differences across simulation conditions.

One interesting point for memory predictions is that even though people did not think they would have a differential memory performance for positive and negative scenarios, subsequent memory results revealed otherwise. Namely, there was no main effect of emotional valence for JOLs neither for past nor for future episodes. Nevertheless, the memory performance was significantly greater for positive episodes (for identical simulation trials) and would-be-positive episodes (for alternative simulation trials) in both experiments. Typically, research evaluating the influence of emotional quality on memory monitoring has shown that people give higher JOLs for emotional information than for neutral information (Hourihan et al., 2017; Tauber \& Dunlosky, 2012; Witherby \& Tauber, 2018; Zimmerman \& Kelley, 2010). Zimmerman and Kelley
(2010), for example, have found that people give higher predictions for both positive and negative words than for neutral words, although this pattern of $\mathrm{JOL}$ did not match with actual recall. In their study, although freerecall performance was better for emotional words than neutral words, cued-recall test generated greater performance for positive emotional words (but not for negative emotional words). In the present study, we did not use neutral episodes for its having very little relevance when engaging in imagination of the alternative consequences of events in everyday life. Still, people seem to be failing at predicting their subsequent memory performance such that JOLs were not different for positive and negative episodes, and that actual recall was better for positive and would-be-positive trials in the cued recall test.

There were some limitations of the present research. One methodological issue is regarding the possibility that the participants in the second experiment may have actually experienced some of the scenarios that they had to simulate. Although one would expect that the probability of experiencing an event's positive or negative outcome should be to the same extent, it would be a good idea to check that the events presented in the experiment do not correspond to actual events in future studies. A second issue bears on how to interpret our findings of superior memory performance found for would-be-positive events. People consistently gave higher vividness and plausibility ratings for positive episodes in both experiments. It has also been shown that would-be-positive conditionals are more commonplace as compared to wouldbe-negative conditionals. It is possible that people perceive would-be-positive events as also more plausible and/or vivid and therefore have easier time remembering the episodes that are simply perceived as more plausible and/or vivid. To test this alternative interpretation, future research may assess the relationship between phenomenological ratings of conditional propositions and later recall performance.

Our results match with the findings showing that healthy adults typically have a positive outlook (Sharot, 2011; Sharot et al., 2007). Having optimistic thoughts about future has some functional-adaptive roles as it influences psychological well-being and motivation (for a review, see Schacter, 2012). The present study adds to these findings and extends them by demonstrating positivity bias for reconstructions of past simulations as well. Finally, through judgments of learning, we also show that adults are not aware of their tendency to preferentially remember their positive or would-be-positive memories, neither for past nor future reconstructions. In other words, healthy adults have a general tendency to remember positive and potentially positive events and to forget negative or potentially negative events, and they are completely unaware of their tendency to selectively remember and forget these hypothetical scenarios both in the imagined past and future. In light of these findings, investigating the effects of reconstructing the past and the 
future on metamemory and memory in populations which do not experience this positivity bias, such as patients with depression, would be of interest for future studies.

\section{Acknowledgments}

This work has been conducted for partial fulfilment of senior thesis project requirements for Belgin Ünal. This work has been funded by The Scientific and Technological Research Council of Turkey (Türkiye Bilimsel ve Teknolojik Araştırma Kurumu) Program Code 2209A Research Projects Fellowship for Undergraduate Students Term 2017/2, Grant number: 1919B011701988.

\section{Disclosure statement}

No potential conflict of interest was reported by the author(s).

\section{Funding}

This work has been conducted for partial fulfilment of senior thesis project requirements for Belgin Ünal. This work has been funded by The Scientific and Technological Research Council of Turkey (Türkiye Bilimsel ve Teknolojik Araştırma Kurumu) Program Code 2209A Research Projects Fellowship for Undergraduate Students Term 2017/2 [grant number 1919B011701988].

\section{ORCID}

Miri Besken (1) http://orcid.org/0000-0002-8024-4173

\section{References}

Addis, D. R., Pan, L., Vu, M. A., Laiser, N., \& Schacter, D. L. (2009). Constructive episodic simulation of the future and the past: Distinct subsystems of a core brain network mediate imagining and remembering. Neuropsychologia, 47(11), 2222-2238. https:// doi.org/10.1016/j.neuropsychologia.2008.10.026

Alter, A. L., \& Oppenheimer, D. M. (2008). Effects of fluency on psychological distance and mental construal (or why New York is a large city, but New York is a civilized jungle): Research article. Psychological Science, 19(2), 161-167. https://doi.org/10.1111/j. 1467-9280.2008.02062.x

Alter, A. L., \& Oppenheimer, D. M. (2009). Uniting the tribes of fluency to form a metacognitive nation. Personality and Social Psychology Review, 13(3), 219-235. https://doi.org/10.1177/1088868309341564

Atance, C. M., \& O'Neill, D. K. (2001). Episodic future thinking. Trends in Cognitive Sciences, 5(12), 533-539. https://doi.org/10.1016/S13646613(00)01804-0

Barsics, C., Van der Linden, M., \& D'Argembeau, A. (2016). Frequency, characteristics, and perceived functions of emotional future thinking in daily life. Quarterly Journal of Experimental Psychology, 218, 1-17. https://doi.org/10.1080/17470218.2015.1051560.

Bartlett, F. F. C. (1932). Remembering: An experimental and social study. Cambridge University.

Bates, D. M., Maechler, M., \& Bolker, B. M. (2011). Package "Ime4". CRAN. http://lme4.r-forge.r-project.org/

Begg, I., Duft, S., Lalonde, P., Melnick, R., \& Sanvito, J. (1989). Memory predictions are based on ease of processing. Journal of Memory and Language, 28(5), 610-632. https://doi.org/10.1016/0749-596X (89)90016-8

Benjamin, A. S., Bjork, R. A., \& Schwartz, B. L. (1998). The mismeasure of memory: When retrieval fluency is misleading as a metamnemonic index. Journal of Experimental Psychology: General, 127(1), 55-68. https://doi.org/10.1037/0096-3445.127.1.55
Besken, M. (2016). Picture-perfect is not perfect for metamemory: Testing the perceptual fluency hypothesis with degraded images. Journal of Experimental Psychology: Learning, Memory, and Cognition, 42(9), 1417-1433. https://doi.org/10.1037/xIm0000246

Besken, M. (2018). Generating lies produces lower memory predictions and higher memory performance than telling the truth: Evidence for a metacognitive illusion. Journal of Experimental Psychology: Learning, Memory, and Cognition, 44(3), 465-484. https://doi.org/ 10.1037/xIm0000459

Besken, M., \& Mulligan, N. W. (2013). Easily perceived, easily remembered? Perceptual interference produces a double dissociation between metamemory and memory performance. Memory \& Cognition, 41(6), 897-903. https://doi.org/10.3758/s13421-0130307-8

Byrne, R. (2016). Counterfactual thought. Annual Review of Psychology, 67(1), 135-157. https://doi.org/10.1146/annurev-psych-122414033249

Castel, A. D., McCabe, D. P., \& Roediger, H. L. (2007). Illusions of competence and overestimation of associative memory for identical items: Evidence from judgments of learning. Psychonomic Bulletin and Review, 14(1), 107-111. https://doi.org/10.3758/BF03194036

D'Argembeau, A., \& Van Der Linden, M. (2004). Phenomenal characteristics associated with projecting oneself back into the past and forward into the future: Influence of valence and temporal distance. Consciousness and Cognition, 13(4), 844-858. https://doi.org/10. 1016/j.concog.2004.07.007

De Brigard, F., Addis, D. R., Ford, J. H., Schacter, D. L., \& Giovanello, K. S. (2013). Remembering what could have happened: Neural correlates of episodic counterfactual thinking. Neuropsychologia, 51(12), 2401-2414. https://doi.org/10.1016/j.neuropsychologia.2013.01. 015

De Brigard, F., \& Giovanello, K. S. (2012). Influence of outcome valence in the subjective experience of episodic past, future, and counterfactual thinking. Consciousness and Cognition, 21(3), 1085-1096. https://doi.org/10.1016/j.concog.2012.06.007

De Brigard, F., Giovanello, K. S., Stewart, G. W., Lockrow, A. W., O'Brien, M. M., \& Spreng, R. N. (2016). Characterizing the subjective experience of episodic past, future, and counterfactual thinking in healthy younger and older adults. Quarterly Journal of Experimental Psychology, 69(12), 2358-2375. https://doi.org/10. 1080/17470218.2015.1115529

De Brigard, F., \& Parikh, N. (2019). Episodic counterfactual thinking. Current Directions in Psychological Science, 28(1), 59-66. https:// doi.org/10.1177/0963721418806512

Faul, F., Erdfelder, E., Buchner, A., \& Lang, A.-G. (2009). Statistical power analyses using G*Power 3.1. Behavior Research Methods, 41(4), 1149-1160. https://doi.org/10.3758/BRM.41.4.1149

Gerlach, K. D., Dornblaser, D. W., \& Schacter, D. L. (2014). Adaptive constructive processes and memory accuracy: Consequences of counterfactual simulations in young and older adults. Memory, 22(1), 145-162. https://doi.org/10.1080/09658211.2013.779381

Grysman, A., Prabhakar, J., Anglin, S. M., \& Hudson, J. A. (2013). The time travelling self: Comparing self and other in narratives of past and future events. Consciousness and Cognition, 22(3), 742-755. https://doi.org/10.1016/j.concog.2013.04.010

Grysman, A., Prabhakar, J., Anglin, S. M., \& Hudson, J. A. (2015). Selfenhancement and the life script in future thinking across the lifespan. Memory, 23(5), 774-785. https://doi.org/10.1080/09658211. 2014.927505

Hassabis, D., \& Maguire, E. A. (2007). Deconstructing episodic memory with construction. Trends in Cognitive Sciences, 11(7), 299-306. https://doi.org/10.1016/j.tics.2007.05.001

Hertzog, C., Dunlosky, J., Emanuel Robinson, A., \& Kidder, D. P. (2003). Encoding fluency is a cue used for judgments about learning Journal of Experimental Psychology: Learning, Memory, and Cognition, 29(1), 22-34.https://doi.org/10.1037/0278-7393.29.1.22

Hertzog, C., Hines, J. C., \& Touron, D. R. (2013). Judgments of learning are influenced by multiple cues in addition to memory for past test 
accuracy. Archives of Scientific Psychology, 1(1), 23-32. https://doi. org/10.1037/arc0000003

Hourihan, K. L., \& Bursey, E. (2017). A misleading feeling of happiness: Metamemory for positive emotional and neutral pictures. Memory, 25(1), 35-43. https://doi.org/10.1080/09658211.2015.1122809

Hourihan, K. L., Fraundorf, S. H., \& Benjamin, A. S. (2017). The influences of valence and arousal on judgments of learning and on recall. Memory and Cognition, 45(1), 121-136. https://doi.org/10.3758/ s13421-016-0646-3

Koriat, A., \& Bjork, R. A. (2006). Illusions of competence during study can be remedied by manipulations that enhance learners' sensitivity to retrieval conditions at test. Memory \& Cognition, 34(5), 959-972. https://doi.org/10.3758/BF03193244

Koriat, A., \& Ma'ayan, H. (2005). The effects of encoding fluency and retrieval fluency on judgments of learning. Journal of Memory and Language, 52(4), 478-492. https://doi.org/10.1016/j.jml.2005.01.001

Miele, D. B., Finn, B., \& Molden, D. C. (2011). Does easily learned mean easily remembered? It depends on your beliefs about intelligence. Psychological Science, 22(3), 320-324. https://doi.org/10.1177/ 0956797610397954

Mueller, M. L., Tauber, S. K., \& Dunlosky, J. (2013). Contributions of beliefs and processing fluency to the effect of relatedness on judgments of learning. Psychonomic Bulletin \& Review, 20(2), 378-384. https://doi.org/10.3758/s13423-012-0343-6

Nasco, S. A., \& Marsh, K. L. (1999). Gaining control through counterfactual thinking. Personality and Social Psychology Bulletin, 25(5), 557569. https://doi.org/10.1177/0146167299025005002

Nelson, T. O., \& Dunlosky, J. (1991). When people's judgments of learning (JOLs) are extremely accurate at predicting subsequent recall: The "delayed-JOL effect". Psychological Science, 2(4), 267-271. https://doi.org/10.1111/j.1467-9280.1991.tb00147.x

Newby-Clark, I. R., \& Ross, M. (2003). Conceiving the past and future. Personality and Social Psychology Bulletin, 29(7), 807-818. https:// doi.org/10.1177/0146167203029007001

Nietzsche, F. (2002). Nietzsche: Beyond good and evil: Prelude to a philosophy of the future. Cambridge University Press.

Nomi, J. S., Rhodes, M. G., \& Cleary, A. M. (2013). Emotional facial expressions differentially influence predictions and performance for face recognition. Cognition and Emotion, 27(1), 141-149. https://doi.org/10.1080/02699931.2012.679917

Özbek, M., Bohn, A., \& Berntsen, D. (2017). Imagining the personal past: Episodic counterfactuals compared to episodic memories and episodic future projections. Memory \& Cognition, 45(3), 375-389. https://doi.org/10.3758/s13421-016-0671-2

Özbek, M., Bohn, A., \& Berntsen, D. (2018). Why do I think and talk about it? Perceived functions and phenomenology of episodic counterfactual thinking compared with remembering and future thinking. Quarterly Journal of Experimental Psychology, 71(10), 2101-2114. https://doi.org/10.1177/1747021817738731

Painter, J. M., \& Kring, A. M. (2015). Back to the future: Similarities and differences in emotional memories and prospections. Applied Cognitive Psychology, 29(2), 271-279. https://doi.org/10.1002/acp. 3105

Rasmussen, A. S., \& Berntsen, D. (2013). The reality of the past versus the ideality of the future: Emotional valence and functional differences between past and future mental time travel. Memory and Cognition, 41(2), 187-200. https://doi.org/10.3758/s13421-0120260-y

$R$ Core Team. (2013). R: A language and environment for statistical computing. R Foundation for Statistical Computing. http://www.Rproject.org/.

Rhodes, M. G., \& Castel, A. D. (2008). Memory predictions are influenced by perceptual information: Evidence for metacognitive illusions. Journal of Experimental Psychology: General, 137(4), 615625. https://doi.org/10.1037/a0013684
Rhodes, M. G., \& Castel, A. D. (2009). Metacognitive illusions for auditory information: Effects on monitoring and control. Psychonomic Bulletin and Review, 16(3), 550-554. https://doi.org/10.3758/PBR. 16.3.550

Roese, N. J. (1997). Counterfactual thinking. Psychological Bulletin, 121 (1), 133-148. https://doi.org/10.1037/0033-2909.121.1.133

Roese, N. J., \& Morrison, M. (2009). The psychology of counterfactual thinking. Historical Social Research, 34(2), 16-26. https://doi.org/10. 12759/hsr.34.2009.2.16-26.

Schacter, D. L. (2012). Adaptive constructive processes and the future of memory. American Psychologist, 67(8), 603-613. https://doi.org/ 10.1037/a0029869

Schacter, D. L., Addis, D. R., Hassabis, D., Martin, V. C., Spreng, R. N., \& Szpunar, K. K. (2012). The future of memory: Remembering, imagining, and the brain. Neuron, 76(4), 677-694. https://doi.org/10.1016/j. neuron.2012.11.001

Schacter, D. L., Benoit, R. G., De Brigard, F., \& Szpunar, K. K. (2015). Episodic future thinking and episodic counterfactual thinking: Intersections between memory and decisions. Neurobiology of Learning and Memory, 117, 14-21. https://doi.org/10.1016/j.nlm.2013.12.008

Sharot, T. (2011). The optimism bias. Pantheon Books. https://doi.org/ 10.1016/j.cub.2011.10.030.

Sharot, T., Riccardi, A. M., Raio, C. M., \& Phelps, E. A. (2007). Neural mechanisms mediating optimism bias. Nature, 450(7166), 102105. https://doi.org/10.1038/nature06280

Shepperd, J. A., Klein, W. M. P., Waters, E. A., \& Weinstein, N. D. (2013). Taking stock of unrealistic optimism. Perspectives on Psychological Science, 8(4), 395-411. https://doi.org/10.1177/1745691613485247

Szpunar, K. K. (2010). Episodic future thought: An emerging concept. Perspectives on Psychological Science, 5(2), 142-162. https://doi. org/10.1177/1745691610362350

Szpunar, K. K., Addis, D. R., McLelland, V. C., \& Schacter, D. L. (2013). Memories of the future: New insights into the adaptive value of episodic memory. Frontiers in Behavioral Neuroscience, 7, 47. https:// doi.org/10.3389/fnbeh.2013.00047

Szpunar, K. K., Addis, D. R., \& Schacter, D. L. (2012). Memory for emotional simulations: Remembering a rosy future. Psychological Science, 23(1), 24-29. https://doi.org/10.1177/0956797611422237

Tauber, S. K., \& Dunlosky, J. (2012). Can older adults accurately judge their learning of emotional information? Psychology and Aging, 27 (4), 924-933. https://doi.org/10.1037/a0028447

Tulving, E. (2002). Episodic memory: From mind to brain. Annual Review of Psychology, 53(1), 1-25. https://doi.org/10.1146/annurev. psych.53.100901.135114

Van Hoeck, N., Ma, N., Ampe, L., Baetens, K., Vandekerckhove, M., \& Van Overwalle, F. (2013). Counterfactual thinking: An fMRI study on changing the past for a better future. Social Cognitive and Affective Neuroscience, 8(5), 556-564. https://doi.org/10.1093/scan/ nss031

Weinstein, N. D. (1980). Unrealistic optimism about future life events. Journal of Personality and Social Psychology, 39(5), 806-820. https://doi.org/10.1037/0022-3514.39.5.806

Witherby, A. E., \& Tauber, S. K. (2018). Monitoring of learning for emotional faces: How do fine-grained categories of emotion influence participants' judgments of learning and beliefs about memory? Cognition and Emotion, 32(4), 860-866. https://doi.org/ 10.1080/02699931.2017.1360252

Yue, C. L., Castel, A. D., \& Bjork, R. A. (2013). When disfluency is-and is not-a desirable difficulty: The influence of typeface clarity on metacognitive judgments and memory. Memory \& Cognition, 41 (2), 229-241. https://doi.org/10.3758/s13421-012-0255-8

Zimmerman, C. A., \& Kelley, C. M. (2010). "I'll remember this!" Effects of emotionality on memory predictions versus memory performance. Journal of Memory and Language, 62(3), 240-253. https://doi.org/10. 1016/j.jml.2009.11.004 